\title{
COVID-19 in Northern Italy: An integrative overview of factors possibly influencing the sharp increase of the outbreak (Review)
}

\author{
MARINA GOUMENOU ${ }^{1 *}$, DIMOSTHENIS SARIGIANNIS ${ }^{2,3^{*}}$, ARISTIDIS TSATSAKIS ${ }^{1,4^{*}}$, OURANIA ANESTI ${ }^{1,3}$, \\ ANCA OANA DOCEA ${ }^{5}$, DIMITRIOS PETRAKIS ${ }^{1}$, DIMITRIS TSOUKALAS ${ }^{6}$, RONALD KOSTOFF ${ }^{7}$, \\ VALERI RAKITSKII ${ }^{8}$, DEMETRIOS A. SPANDIDOS $^{9}$, MICHAEL ASCHNER $^{4,10}$ and DANIELA CALINA ${ }^{11}$ \\ ${ }^{1}$ Center of Toxicology Science and Research, Medical School, University of Crete, 71003 Heraklion; \\ ${ }^{2}$ HERACLES Research Center on the Exposome and Health, Center for Interdisciplinary Research and Innovation, \\ Aristotle University of Thessaloniki, 57001 Thessaloniki, Greece; ${ }^{3}$ School for Advanced Studies IUSS, Science, \\ Technology and Society Department, I-25100 Pavia, Italy; ${ }^{4}$ I.M. Sechenov First Moscow State Medical University \\ (Sechenov University), 119146 Moscow, Russia; ${ }^{5}$ Department of Toxicology, University of Medicine and \\ Pharmacy of Craiova, 200349 Craiova, Romania; ${ }^{6}$ Metabolomic Medicine, Health Clinics for Autoimmune \\ and Chronic Diseases, 10674 Athens, Greece; ${ }^{7}$ Research Affiliate, School of Public Policy, Georgia Institute of \\ Technology, Gainesville, VA 20155, USA; ${ }^{8}$ Federal Scientific Center of Hygiene, F.F. Erisman, 141014 Moscow, Russia; \\ ${ }^{9}$ Laboratory of Clinical Virology, Medical School, University of Crete, 71003 Heraklion, Greece; ${ }^{10}$ Department of \\ Molecular Pharmacology, Albert Einstein College of Medicine, New York, NY 10461, USA; ${ }^{11}$ Department \\ of Clinical Pharmacy, University of Medicine and Pharmacy of Craiova, 200349 Craiova, Romania
}

Received March 23, 2020; Accepted April 16, 2020

DOI: $10.3892 / \mathrm{mmr} .2020 .11079$

\begin{abstract}
Italy is currently one of the countries seriously affected by the COVID-19 pandemic. As per 10 April 2020, 147,577 people were found positive in a total of 906,864 tests performed and 18,849 people lost their lives. Among all cases, $70.2 \%$ of positive, and $79.4 \%$ of deaths occurred in the provinces of Northern Italy (Lombardi, Emilia Romagna, Veneto and Piemonte), where the outbreak first started. Originally, it was considered that the high number of positive cases and deaths in Italy resulted from COVID-19 initially coming to Italy from China, its presumed country of origin. However, an analysis of the factors that played a role in the extent of this outbreak
\end{abstract}

Correspondence to: Professor Aristidis Tsatsakis or Dr Marina Goumenou, Center of Toxicology Science and Research, Medical School, University of Crete, 71003 Heraklion, Greece

E-mail: tsatsaka@uoc.gr

E-mail:marina.goumenou@gmail.com

*Contributed equally

Abbreviations: ISS, Istituto Superiore di Sanità; ACE-i, angiotensin converting enzyme inhibitors; ARBs, angiotensin receptor blockers; ACE2, angiotensin converting enzyme 2; ESC, European Society of Cardiology; EEA, European Environment Agency; IQR, interquartile range; TMPRSS2, transmembrane protease serine 2

Key words: COVID-19, SARS-CoV-2, coronavirus, risk factors, Italy, pandemic diseases, public health is needed. Evaluating which factors could be specific for a country and which might contribute the most is nevertheless complex, with accompanying high uncertainty. The purpose of this work is to discuss some of the possible contributing factors and their possible role in the relatively high infection and death rates in Northern Italy compared to other areas and countries.

\section{Contents}

1. General context

2. Demographics and health

3. Societal customs and epidemic-specific attitudes

4. Environmental factors

5. Administrative issues

6. Discussion

7. Conclusions and lesson learned

\section{General context}

Evolution of COVID-19 outbreak in Italy and the patient characteristics. After the beginning of the COVID-19 outbreak in China, when information of its characteristics began arriving in Europe, the Italian Ministry of Health established a task-force group for the coordination of all COVID-19 related issues on 22 January. On 31 January, Italy declared a public health emergency (1). The first cases of positive infections attributed to COVID-19 were confirmed by the Superior Health Institute (Istituto Superiore di Sanità, ISS) on 30 January, 
referring to two Chinese tourists already hospitalised from 29 January, in Rome. The first indigenous case, an Italian man aged 38 years, was confirmed positive 3 weeks later, on 21 February in Codogno (named as patient 'one') (1). How patient one was infected remains unknown, though there are some indications that COVID-19 might have come to Italy from Germany towards the end of January. In the next two days, 36 new cases appeared, none of which had contact with the first patient or anyone with the COVID-19 infection. This was the beginning of one of the largest and most uncontrolled groups of patients with COVID-19 in the world, which rapidly triggered intra-community transmission in Italy. Until 24 February (3 days later), where the official graphs of disease incidence start, 221 positive cases and 7 deaths were recorded in Italy. From 24 February until 3 March, the number of Italians whose infections were attributed to SARS-CoV-2 increased 10-fold (2,263 positives and 79 deaths). Four weeks later (30 March), there were a total of 75,528 positive cases and 11,591 deaths (ca. 150 times increase) in Italy. The hospitals and medical personnel in Northern Italy became overwhelmed by the tens of thousands of victims (in just a few weeks) whose infections were attributed to SARS-CoV-2. On April 10, there was a total of 147,577 positive cases and 18,849 deaths (Fig. 1) (2,3). An analysis of the sub-set of patients whose deaths were attributed to COVID-19 (4) was performed with a sample of 1,453 deaths. This analysis showed that $96.5 \%$ of people who died were suffering from one or more pre-existing medical conditions, such as hypertension (69.9\%), diabetes mellitus (31.8\%), and ischemic cardiomyopathy (28.0\%) (5). Deaths were associated with one, two or three co-existing comorbidities in $14.8,20.7$ and $61.0 \%$ of cases, respectively. It is apparent that the existence of comorbidities is associated with the average age of 78-years of those who died (median 80, range 5-100, IQR 73-85). Deaths of those less than 50 years of age were $1.2 \%$ of the cases. The average age of infected people is currently 62 years (32.9\% women and $67.1 \%$ men), but this reflects most probably the average age of people receiving medical assistance who were consequently tested. Among all cases in Italy, $70.2 \%$ those who tested positive, and $79.4 \%$ of those who died came from the four Northern Italy regions (Lombardi, Emilia Romagna, Veneto and Piemonte) where the outbreak started (Table I and Fig. 2).

The measures. As shown in the timeline in Fig. 3, the first measures taken against the COVID-19 pandemic announced on 30 January was with the closure of direct flights from China. Measures in Lombardi started at February (6), after the first positive case of an Italian person in Codogno on 21 February, locking down specific areas. On 4 March, school closure was announced at the national level, and a series of mobility restriction measures started to be applied.

On March 8, following ca. 7,000 positive cases and ca. 370 deaths recorded, restriction of movement from the Northern Italy infected areas to the rest of Italy was announced. This announcement created an immediate wave of people leaving the infected areas and moving to the rest of Italy leading to a new restriction one day later, forbidding the mobility among provinces in all of Italy. On March 22, when deaths had increased to ca. 800 deaths per day, closure of all industries not related to food, medicines and strategic

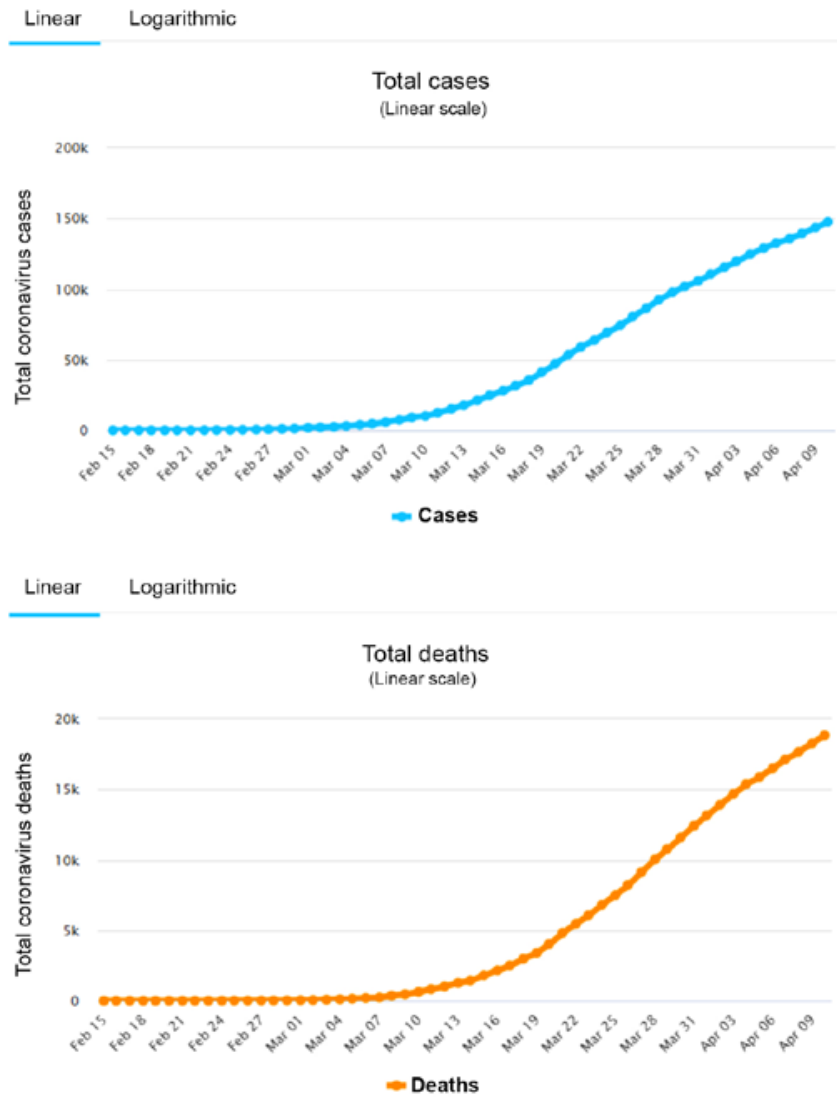

Figure 1. Monitoring of COVID-19 positive cases and deaths in Italy from 15 February to 9 April 2020 (2).

needs was ordered. For the general population, mobility was allowed only for serious reasons, such as specific family needs (e.g., support of elderly family members), critical employment (e.g., medical doctors, nurses, supermarket employees), shopping from supermarkets and purchase of medicines, as well as taking out domestic dogs. A decline in the rate of increase of new cases were recorded, thus leading the Director of the Superior Health Institute, Silvio Brusaferro, to state on April 10 that 'The contagion curve signals a situation in decline but we must not let down our guard' (8). The most recent reduction of admittance of COVID-19 cases to the emergency department of the aforementioned Northern Italy regions appears to support this evaluation.

The patient 'zero' discussion. The first confirmed COVID-19 patients in Italy were a couple of Chinese tourists (husband and wife 67 and 66 years old, respectively). The couple entered Italy on 23 January from the airport of Milan-Malpensa, passing from Verona and Parma where they rented a car and drove to Rome. In Rome, they manifested symptoms, and were confirmed as COVID-19 positives on 30 January. A phylogenetic analysis indicated that the two persons were infected in China, probably around 19 January, before their entrance to Italy (9). These patients were not characterized as patients 'zero' or 'one'.

Twenty-two days later, on 21 February, an Italian man was confirmed positive and named as patient 'one'. The trace analysis of the so-called patient 'one' gave indications that COVID-19 might have come to Italy from Germany about the 
Table I. COVID-19 outbreak in Northern Italy up to 10 April 2020.

\begin{tabular}{|c|c|c|c|c|c|c|c|c|}
\hline & \multicolumn{3}{|c|}{ Absolute figures } & \multicolumn{2}{|c|}{$\%$} & \multicolumn{3}{|c|}{$\%$ of total } \\
\hline & Positive cases & Tests & Deaths & Pos/tests & Deaths/pos & Positive cases & Tests & Deaths \\
\hline Lombardi & 56,048 & 186,325 & 10,238 & 30.1 & 18.3 & 38.0 & 20.5 & 54.3 \\
\hline Emilia Romagna & 19,128 & 85,884 & 2,397 & 22.3 & 12.5 & 13.0 & 9.5 & 12.7 \\
\hline Veneto & 13,421 & 180,700 & 793 & 7.4 & 5.9 & 9.1 & 19.9 & 4.2 \\
\hline Piemonte & 15,012 & 57,457 & 1,532 & 26.1 & 10.2 & 10.2 & 6.3 & 8.1 \\
\hline Total & 147,577 & 906,864 & 18,849 & & & 70.2 & 56.3 & 79.4 \\
\hline
\end{tabular}

Pos, positive.

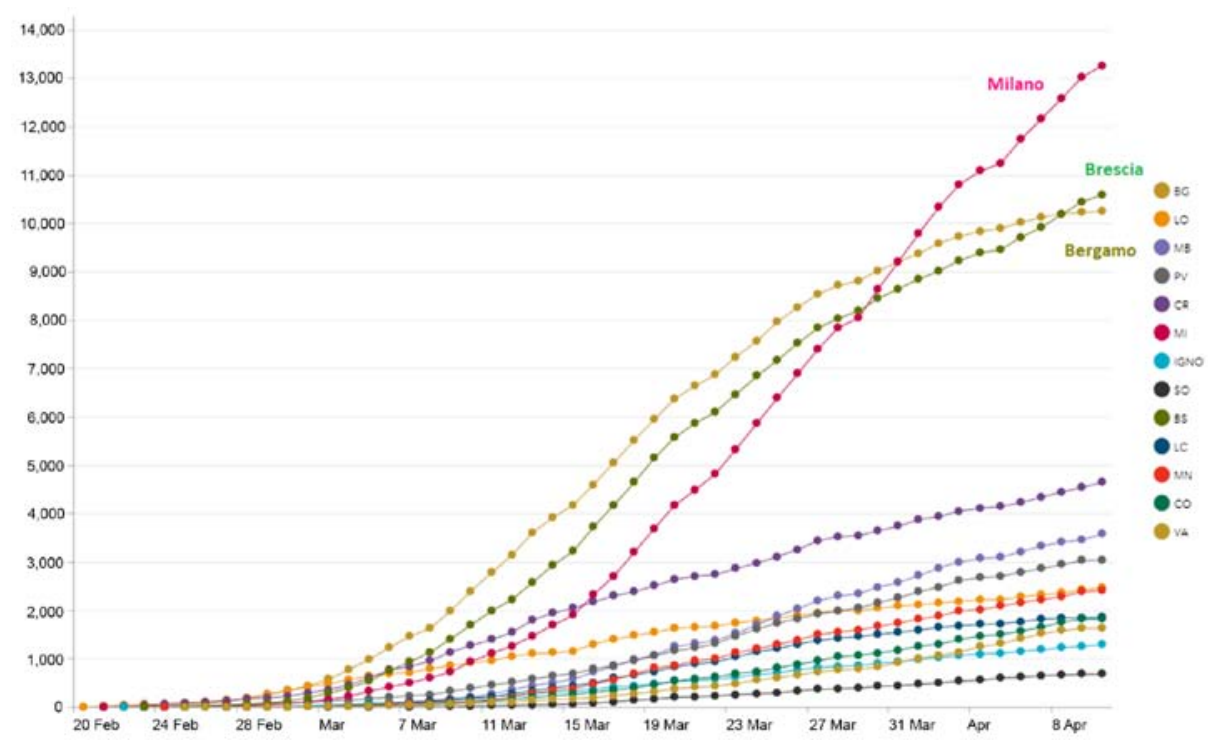

Figure 2. Infection curves (cumulative of positives) of the provinces of Lombardy region (7).

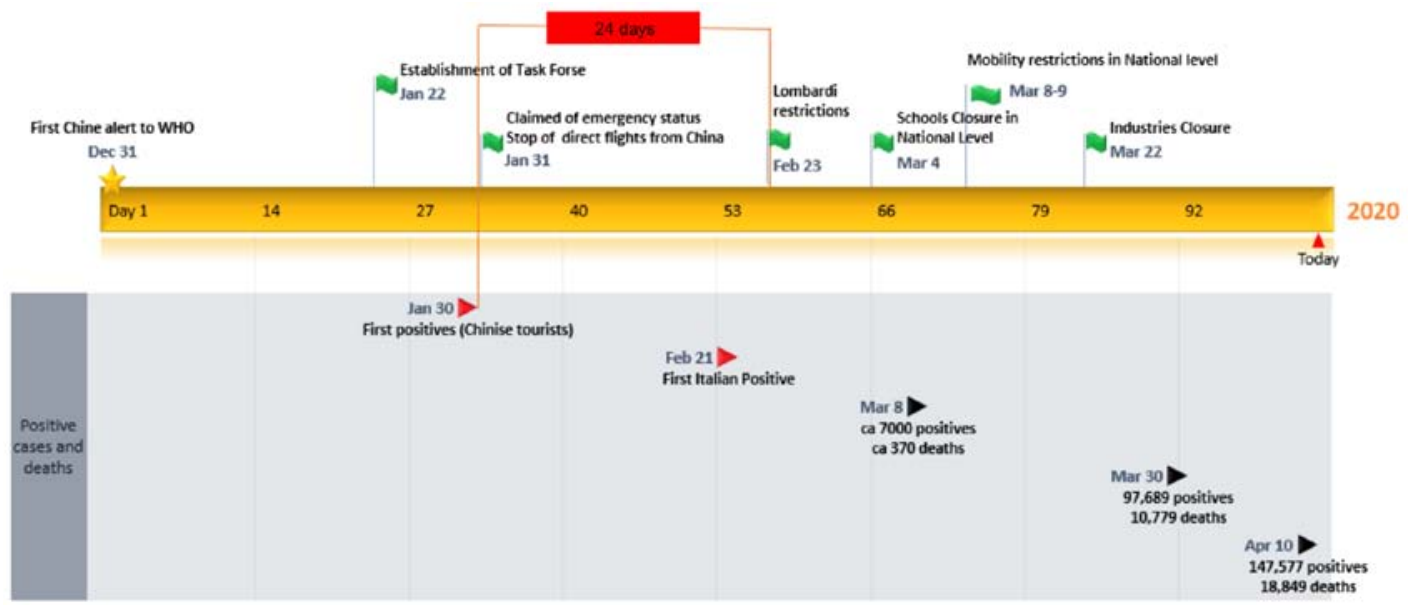

Figure 3. The timeline of measures taken in Italy during the evolution of the COVID-19 epidemic.

end of January. Up to now, the patient 'zero' that infected this patient (assuming the infection came from another human), is officially unknown.

Beyond the officially named cases above, there are articles in journals mentioning that an elderly patient with
COVID-19-related symptoms, entered a hospital in Piacenza (Emilia Romagna) on January. Later, he was identified positive and eventually died. Another elderly man entered another hospital in the same area on February 17, and was also confirmed positive later (10). 
Table II. Population density of various countries and cities of interest.

\begin{tabular}{lcc}
\hline Country/city & Population density (persons/km $\left.{ }^{2}\right)$ & Positive cases per million habitants \\
\hline Country & & 2,049 \\
Belgium & 337 & 1,240 \\
France & 104 & 1,366 \\
Germany & 223 & 2,307 \\
Italy & 192 & 3,172 \\
Spain & 92 & 4,231 \\
City & & $5,000(\mathrm{ca})$. \\
Milan & 7,700 & 2,472 \\
Wuhan & 5,823 & $187,946^{\mathrm{a}}$ \\
Lodi (province of Codogno) & 1,109 & 790 \\
Codogno & 790 \\
\hline
\end{tabular}

${ }^{a}$ Extrapolation the one million habitants.

As expected, a thorough discussion in Italian and global journals describes the possibility that a considerable number of infected Chinese people entered Italy. The Guardian mentioned in an article of 25 March cases of prejudice against Chinese people in Italy, that ca. 310,000 Chinese people are living in Italy, being the 3rd largest foreign community, with more than half of them settled in Northern Italy, and ca. 30,000 living and working in Prato (Tuscany), the center of Italian textile industry (11). Though the current consensus in the West is that COVID-19 entered Italy from China, it does not appear that the workers of Prato are the original carriers of the virus, as the initial outbreak of infection was not observed in Prato.

In a mathematical model developed by researchers in Shanghai, it was calculated that 34 unobserved infected people travelling out of China in the very beginning of the epidemic would have been enough to create what we see today (12). Given the fact that commercial collaboration between China and the rest of the world is strong, it is apparent that during January thousands of people (Chinese and Europeans) travelled from China to Europe. Obviously, some of them were already infected, and most probably, their numbers were higher than 34. Considering that Lombardi has 3 very busy international airports (Malpena, Linate, and Bergamo), has strong commerce, and has a great number of international events organized constantly in the area, it is safe to assume that a number of infected people, directly from China but also through other countries (as the case of the so-called Italian patient 'one'), entered Italy in that period. Consequently, it is very probable that it was not only one patient 'zero' but many.

Though direct flight from China to Italy were blocked on 31 January, infected people were already in Italy as proven by the entrance of the infected Chinese tourists already from 23 January. In addition, elimination of direct flights from China, though a first measure, cannot prevent the entrance of infected people from China though transit flights and infected people from other countries.

In conclusion, the number, origin, and identity of patients 'zero' in Italy and other countries will probably remain unknown. What we do know is that asymptomatic patients and patients with mild symptoms remained unidentified, greatly contributing in the spread of the infection.

\section{Demographics and health}

\section{Demographics}

Population density. Italy has a population density of 192 persons $/ \mathrm{km}^{2}$, which is lower than that of other European countries such as Germany (233 persons $/ \mathrm{km}^{2}$ ) and Belgium (337 persons $/ \mathrm{km}^{2}$ ), but higher than Spain $\left(92\right.$ persons $/ \mathrm{km}^{2}$ ) and France (104 persons $/ \mathrm{km}^{2}$ ) (13). Wuhan in China, where the COVID-19 pandemic presumably started, has an urban population of $8,896,900$ persons in an area of $1,528 \mathrm{~km}^{2}$ (density 5,823 persons $/ \mathrm{km}^{2}$ ) (14) (Table II). Considering the sub-provincial and prefecture population and area, the density is estimated at ca. 1,200 persons $/ \mathrm{km}^{2}$ (15). Codogno, the city in Lombardy where the Italian outbreak started, has a population density of 790 persons $/ \mathrm{km}^{2}$ while Milan has a density of 7,700 persons/ $\mathrm{km}^{2}$. As Italy and Spain have higher number of cases per million habitants (16) though lower population density, it is clear that this parameter should be considered per area of frequent mobility of the majority of the population (e.g., city level) rather than in country level. In any case, the population density as a factor for the outbreak in Northern Italy should be evaluated together with other factors that will be discussed below.

Age-distribution. According to Eurostat (17) in 2019, the average age of the population in Italy was 46.7 years, the highest in Europe (EU-28 average 43.1), seven years older than the average age in China and slightly above that in South Korea. Italy has the lowest share of persons of age 0-14 (13.4\%) and the highest share of persons above 65 years $(22.6 \%)$ in the EU. Germany, Portugal and Greece are in the 2nd, 3rd, and 4th places of aged population, after Italy (17) without considerable differences. Up to now, the data regarding the infection and death curves in Germany where the first case was reported around the same time as in Italy, are quite different than the curves in Italy. In Germany, during the first month, 66 cases and 0 deaths were observed vs. 1,049 cases and 29 deaths in Italy while during the second month Germany had 52.547 cases and 
389 deaths vs. 75.528 and 11.591 deaths in Italy. Thus, it is unclear whether the higher age of Italian population might at least partially explain the very high figures of related spread and deaths in Italy. Other factors might also play a role, such as differences in number of tests made, differences in testing for SARS-CoV-2 infection at the population levels and strategy of testing (e.g., only seriously ill individuals), and different coding of causes of death. The aforementioned factors may well explain the surprisingly large difference in spread and case-fatality rates reported across different countries, including Italy, Spain, Germany and China.

Health state. There are various parameters that are related to the health state of a country's population such as smoking habits, sport activities and level of happiness.

Smoking. Smoking increases the expression of the gene for the conversion enzyme of angiotensin 2 (ECA2), the binding receptor for SARS-CoV-2, which explains the increased susceptibility to infection of smokers. Smoking is the leading cause of chronic obstructive pulmonary disease, and an independent risk factor for severe evolution of COVID-19. However, a smoking ban law is in place in Italy since 2005, smoking rate for 2019 was $22 \%$ (9.8\% in the ages $65+$ ) with only $14 \%$ in Northern Italy (18). The smoking rate for Germany for 2019 was ca. $21.6 \%$ with Bavaria and Baden-Württemberg which have the most COVID-19 cases have the lowest smoking rates in Germany (20.6 and $21.3 \%$, respectively) (19). Though there is no doubt that smoking increases susceptibility to COVID-19 symptoms' severity, there is no reason to believe that it is a key parameter for Northern Italy outbreak in comparison with other countries.

Physical activity, obesity and population health index (PHI). In Italy, more than 60\% of persons aged 50-69 years and $65+$ declare middle or high level of physical activity; Northern Italy has higher scores than the average $(20,21)$. Italy has the lowest percentage of overweight population in EU-28, and the second lowest percentage of obesity (22). In ages 65+, 43 and $14 \%$ of the Italian population is considered overweight (BMI 25-29.9) and obese (BMI >30), respectively (23), with Northern Italy having lower values. Regarding various PHI, Italy together with Sweden have the highest values of Lifestyle and Health Behaviors Index and a low PHI regarding deaths due to diseases of respiratory system (24). In a ranking of the Healthiest Countries 2020 by the Bloomberg Healthier Country Index (25), Italy and Spain had the highest scores in Europe, considering various factors such as Health risks (tobacco use, high blood pressure, obesity), healthy diet, outdoor activities, life expectancy, and causes of death. As indicated from the above information, the only element related to the COVID-19 extreme outbreak is related to deaths due to respiratory diseases in the Italian population.

Patient comorbidities. Until 9 April, 83.2\% of deaths in Italy were in patients over 70 years while the infection median age is 62 (vs. 80 for deceased) (4). According to statistical models, the majority of elderly will probably require intensive care, putting pressure on the Italian health care system. Based on existing data, it can be concluded that the deaths caused by COVID-19 occur mainly among the elderly. This clearly means that countries will have to take aggressive protection measures for the protection of the elderly to remain below the critical number of cases that exceeds the capabilities of their health systems. However, Japan, an older nation than Italy (the average age of the Japanese is 47.3 years), had only 59 officially registered deaths on 31 March. So clearly, age, though important, is not the only factor involved.

What is highly related to age is the existence of comorbidities that increase the risk of mortality from COVID-19 infection. Recent statistics on increased mortality in Italy are based on defining COVID-19 deaths as deaths in patients hospitalised for SARS-CoV-2 and with a positive PCR test, independent of pre-existing diseases that could have caused death. This method was selected because no clear criteria for defining COVID-19 deaths are available. Choosing to define COVID-19 death in this way may lead to some level of overestimation of the fatality rate. On the other hand, deaths at home are not subject of testing for COVID-19 and consequently a number of COVID-19 related deaths might not be registered. In any case, ISS reported that 'Acute Respiratory Distress syndrome was observed in the majority of patients (96.7\% of cases), followed by acute renal failure (23.5\%). Superinfection was observed in $11 \%$ and acute cardiac injury in $9.8 \%$ of cases'. In an ideal situation, a global agreement in the way COVID-19 deaths are registered should be established to allow for global monitoring and clear comparisons among countries. This is the only secure way to learn from each other and allow countries of the world to follow best practices in managing such pandemics in the future.

The Italian Public Health Institute (ISS) published on 26 March 2020 an assessment in a sample of 710 hospitalized patients who died, according to which only $2.1 \%$ of the cases had no comorbidities. Whereas, $97.9 \%$ of the cases had one, two or three and more pre-existing comorbidities in the 21.3, 25.9 and $50.7 \%$ of the cases, respectively (26). The most common pre-existing chronic pathologies (diagnosed before contacting the infection) in deceased patients in Italy were: hypertension $-73.0 \%$, old diabetes $-31.3 \%$, ischemic heart disease $-27.8 \%$, atrial fibrillation $-23.7 \%$, chronic renal failure $-22.2 \%$, active cancer in the last 5 years $-17.3 \%$, chronic obstructive pulmonary disease (COPD) - 16.7\% (26). The existence of pre-existing comorbidities does not mean that COVID-19 infection did not contribute to the death of patients, but it does show that the number of deaths in Italy and elsewhere is increasing as a large proportion of patients had other underlying diseases.

Hypertension. An essential risk factor is antihypertensive treatment with angiotensin converting enzyme inhibitors (ACE-i). According to recent data, before hospitalization, 36\% of Italian patients deceased with COVID-19, underwent ACE-i therapy while $16 \%$ was treated with angiotensin receptor blockers (ARBs). It is unclear at this time whether there is a direct link between severe progression and/or death and treatment with ACE-i and/or ARBs or it is just a coincidence caused by old age and high blood pressure itself (27).

In the case of COVID-19, an important element is the molecule that acts as a receptor for the virus: the angiotensin converting enzyme (ACE2) (28). It is found on the surface of cells lining the airways and lungs, facilitating the entry of the virus into the body (29). At the same time, ACE2 is a target of the antihypertensive therapeutic class of ACE-i. Given 
the high prevalence of hypertension among severe cases of COVID-19, it has been hypothesized that hypertensive patients taking these treatments have an increased risk of COVID-19 infection due to the high level of the enzyme to which the virus binds (30).

The European Society of Cardiology (ESC) recommended continuing antihypertensive treatment with these drugs and emphasized the lack of evidence to support the adverse effect (31). High ACE2 levels (also due to anti-hypertensive drug therapy) might even be beneficial, and not adverse, given the competition for the same receptor between ACE2 and viral spike protein for the same ACE2 reception (this is the rationale for a trial initiated currently with ACE2 as basis for two nationwide studies investigating this issue in Italy) (32).

Diabetes mellitus. Diabetes increases the risk of severe evolution of COVID-19, under conditions of glycemic imbalance, and even pulmonary bacterial over-infection. COVID-19 increases the risk of diabetic complications, including diabetic ketoacidosis, an acute complication, with a severe prognosis. The mechanism by which diabetes complicates the evolution of COVID-19 is not known exactly (33).

Studies on other infections that overlap with diabetes describe hyperglycemia as a promoter of immunosuppression. In addition, diabetes is associated with cardiovascular and kidney disease and older age, and all of these factors contribute to the severe evolution of infections. The interaction between diabetes and the virus is complex, and it is not clear whether hyperglycemia contributes to SARS-CoV-2 virulence, or whether it alters carbohydrate metabolism. In addition, the metabolic imbalances caused by diabetes are multiple and lead to a pro-inflammatory and pro-oxidative status in the body, which decreases resistance to the virus. ACE-i, is also used commonly for diabetes patients to prevent diabetic micro- and macro-vascular complications, which can affect the cardiovascular and renal systems. However, as we mentioned above there is no evidence to suggest that ACE-i treatment was discontinued in diabetes during the COVID-19 epidemic (34).

Though the correlation between the death probability of COVID-19 patients and existence of comorbidities is apparent, there is no reason to believe that this is a phenomenon specific for Northern Italy. The comorbidities mentioned above are usually found in the elderly all over the word.

Cancers. Cancer patients are more susceptible to infection than the general population due to the immunosuppression produced by the cancer itself but also by the antineoplastic treatments. Among the groups of patients most at risk of severe infections are those with haematological disorders (leukemia, lymphoma), leukopenia caused by neoplasia and treatment (chronic decrease in the number of leukocytes), low level of immunoglobulins (as in multiple myeloma), chronic immunosuppression by treatments such as corticosteroids or monoclonal antibodies, allogeneic stem cell transplantation or other cell therapies (35).

The pulmonary impairment induced by major cytokine-mediated inflammation underlies severe events in patients with COVID-19. However, the immune system is affected in cancer by overexpression of immunosuppressive cytokines, decreased proinflammatory signals, impaired dendritic cell maturation and increased immunosuppressive leukocyte count (36).

The evolution of COVID-19 in cancer patients has been highlighted in a recent study showing the increased risk of hospitalization, severe evolution and death for oncological patients, as well as shorter duration until the occurrence of severe events (37). The study analyzed 1,590 patients. Of these, $18(1 \%)$ had a history of cancer - a proportion higher than the incidence of cancer in the Chinese population $(0.29 \%$, according to 2005 estimates). Lung cancer was the most common form in infected patients (28\%). Of the 18 oncological patients, 16 had received treatment, of which 4 had been treated by chemotherapy or surgery in the previous month. They were at even greater risk of severe events ( 3 of the 4 patients), compared to those who had been treated long ago (6 of the 14 patients). Compared with the rest of the group, cancer patients were older (63.1 vs. 48.7 years, mean age), more were smokers (22 vs. 7\%), had more severe respiratory manifestations (47 vs. 23\%) and had a more severe CT scan (94 vs. 71\%).

Genetic polymorphisms and susceptibility to COVID-19 in Italy. Genetic predisposition can be a key point related to regional/territorial and ethnic differences on COVID -19 incidence and severity of the disease. Research in the topic of polymorphism related to COVID-19 susceptibility is at the beginning. Still, many studies have been focused mainly on genes such as ACE2 and TMPRSS2 that modulate the expression of angiotensin I, converting enzyme 2 (ACE2) receptor and transmembrane protease serine 2 (TMPRSS2). ACE2 is the receptor used by the S protein of COVID-19 to bind to and to facilitate the attachment to target cells, while TMPRSS2 is implicated in the fusion between viral and cellular membranes by cleaves protein $\mathrm{S}$ at the $\mathrm{S} 2$ and $\mathrm{S} 1 / \mathrm{S} 2$ sites (37-39). Down expression of ACE2 receptors determined by ACE2 polymorphism could decrease the possibility that the virus enters in the organism and have a protective effect. In contrast, the higher expression is associated with higher susceptibility and worst evolution (12). Asselta et al (40), tried to explain the high incidence, severity and sex differences in COVID-19 infection in Italy by investigating the polymorphism of ACE2 and TMPRSS2 genes. However, no difference in ACE2 genes was found that could explained the sex differences or higher susceptibility and mortality in the Italian population. Regarding the genetic variation in TMPRSS2, 3 variants were observed, one exonic variant (p.Val60Met) and 2 haplotypes that are more frequent in Italian population compared to the East Asian population that also determines an increased susceptibility to influenza (40). Further studies should be done in order to validate this hypothesis that can help the physicians to identify risk population and apply personalized preventive and therapeutic strategies.

For the purpose of our analysis, the existing data are very limited to allow to consider this factor as a key contributor for the outbreak, thought this remains a possibility.

\section{Societal customs and epidemic-specific attitudes}

\section{Societal customs}

Indoor social life. In Northern Italy, mainly due to the climate but also as habit, there is a preference to in-door gathering 
Table III. Percentage of Italian urban population exposed to concentrations above EU standards for selected pollutants such as $\mathrm{BaP}, \mathrm{NO}_{2}, \mathrm{O}_{3}, \mathrm{PM} 10$ and PM2.5 for the years 2012-2017 (45).

\begin{tabular}{|c|c|c|c|c|c|c|}
\hline & & 2013 & 2014 & 2015 & 2016 & 2017 \\
\hline $\mathrm{BaP}$ & Annual mean & 2.8 & 1.5 & 7.8 & 5.7 & 6.6 \\
\hline $\mathrm{NO}_{2}$ & Annual mean & 27.5 & 15.7 & 27.9 & 23.2 & 23.8 \\
\hline $\mathrm{O}_{3}$ & Percentile 93.15 & 52.0 & 25.6 & 72.5 & 45.4 & 62.9 \\
\hline PM10 & Percentile 90.41 & 64.9 & 48.9 & 64.9 & 42.5 & 44.2 \\
\hline PM2.5 & Annual mean & 72.0 & 27.0 & 78.3 & 59.2 & 75.0 \\
\hline
\end{tabular}

social activities instead of out-door (out-door shifts in bars and restaurants are less common than in other countries). The COVID-19 outbreak in Northern Italy started at the end of January - beginning of February 2020, when meteorological conditions restrict social activities to indoors, favoring a high rate of viral and bacterial transmission/contamination. Furthermore, it should be noted that elderly people in Northern Italy are very social, and they are used to indoor activities such as dancing and gaming places, probably more frequently than in Southern Italy and other countries. It is also frequent to visit emerging care units for very simple medical cases, a factor that probably contributed further to the observed high rate of contamination.

Family habits. Another important factor that probably contributed significantly to the high rate of contamination is family habits. According to Eurostat data of 2018, in Italy the mean age that young people (which can host the virus without symptoms) leave the parental household is 30.1 years [4th position after Croatia, Malta, and Slovakia (41)]. The EU-28 average is 26.0 years while in Germany, France, Spain, and Greece the average is $23.7,23.7,29.5$ and 29.3 years, respectively (41). In addition, extended families in Italy as well as in the rest of Mediterranean countries are very close with frequent physical contact between them, putting the elderly in Northern Italy at risk. This intergenerational mix may have played an important role in the high infection rate. However, data has shown that other countries with similar family habits, like Greece, avoided such high spread of infection, indicating that more factors likely play a role.

\section{Epidemic-specific attitudes}

Privacy. Searching for other attitudes that might have played a role in the high infection rate in Northern Italy, we came to the following two possible factors. The first factor is related to the level of interpersonal open communication. People in many countries usually avoid speaking and revealing personal information including health issues. In the case of COVID-19 epidemic avoidance to share with friends and colleagues that symptoms appeared, prevents other persons from being alerted, isolate themselves and to ask for medical consultation and/or care in time. However, the level of contribution of this factor in Northern Italy outbreak is difficult to estimate objectively, and it cannot be considered as unique to this case.

Inter-species transmission. A second factor is related to the fact that most of the families in Northern Italy have dogs. Taking-out the dogs is permitted and exempted from the mobility restrictions. The case of inter-species transmission between humans and dogs is not yet scientifically examined but based on a recent study we performed there are no reasons to believe that this transmission possibility does not exist (42). However, in the absence of adequate experimental studies also this factor cannot be considered at present; yet it remains as a possibility.

\section{Environmental factors}

Po valley in Northern Italy is the area between the Alps and the Appennines and it includes the regions of Lombardia, Emilia Romagna, Piemonte, Veneto, Friuli Venezia Giulia (and all 'red' zones of Codogno, Lodi, Cremona, Padua, Bergamo, and Brescia) (Fig. 3) (43). Po valley is the industrial center and the most densely populated area of Italy. Due to the large number of industries as well as the climate of this area (high humidity, plain, very low wind intensity), Po valley has a very poor air quality, characterized by high concentrations of fine particles, nitrogen dioxide, and ozone) (Figs. 4-6; Table III) $(44,45)$.

As indicated by European Environment Agency (EEA) the worst cases in Europe regarding the risk accumulation due to exceedance of EU limits and exposure of the urban population to all three pollutants simultaneously $\left(\mathrm{PM}, \mathrm{O}_{3}\right.$, and $\left.\mathrm{NO}_{2}\right)$, refer to 2.0 million inhabitants in the Po valley and 0.5 million inhabitants in Greece (44).

Poor air quality is associated with chronic lung disease and decreased lifespan.PM can deteriorate lung and cardiovascular diseases and has been shown to decrease life expectancy. $\mathrm{NO}_{2}$ can affect the lung, the liver, and the blood, increase the effects of already existing lung diseases as well as to increase the susceptibility to respiratory infections. Inhalation of $\mathrm{O}_{3}$ leads to decrease of the inhaled oxygen having as secondary effect overload of the heart (46). For this reason, it further increases the risk for people with respiratory and/or heart diseases.

Based on data above we believe that as high air pollution in Northern Italy is an area specific factor and highly related with possible compromise of the health of respiratory system of the population, it could be an important contributing factor in the COVID-19 extreme outbreak.

Finally, any lifestyle, iatrogenic, biotoxic, or environmental/occupational factor, or especially combinations of such factors, that have been shown in the biomedical literature to adversely impact the immune system cannot be ruled out as contributing to increased incidence of viral infections. Identifying any such potential contributing factors, and attributing them to any particular region or country, requires a separate and major study. 


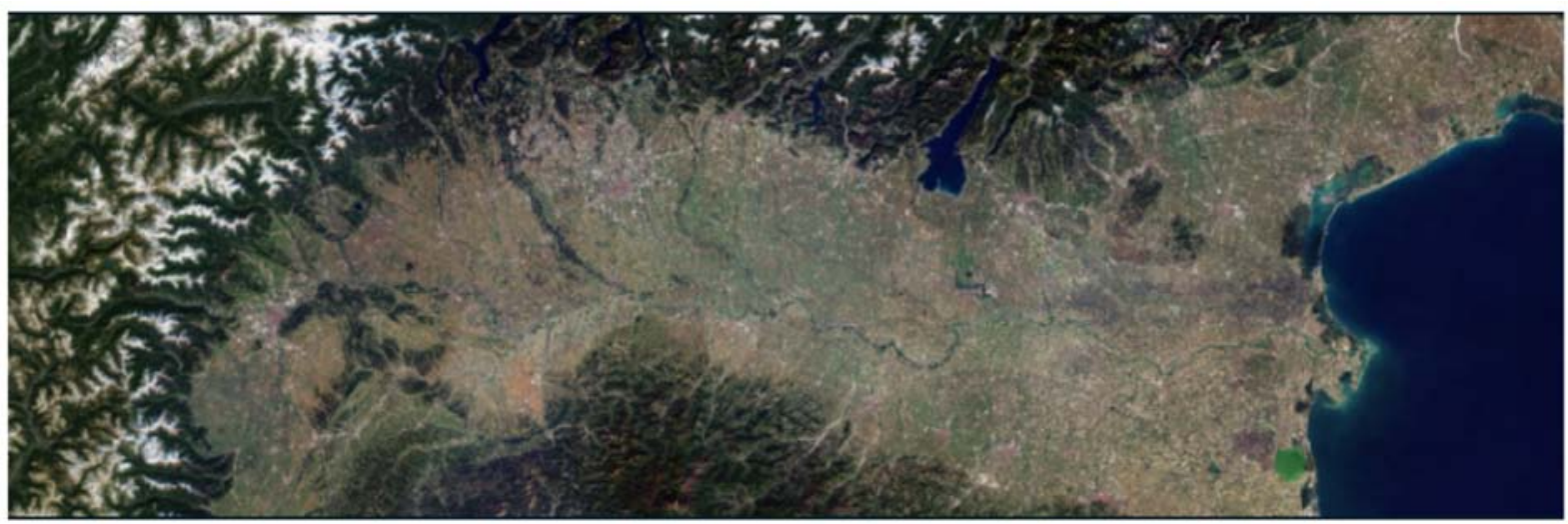

Figure 4. Copernicus Sentinel-2 image of Po Valley, Northern Italy (43).

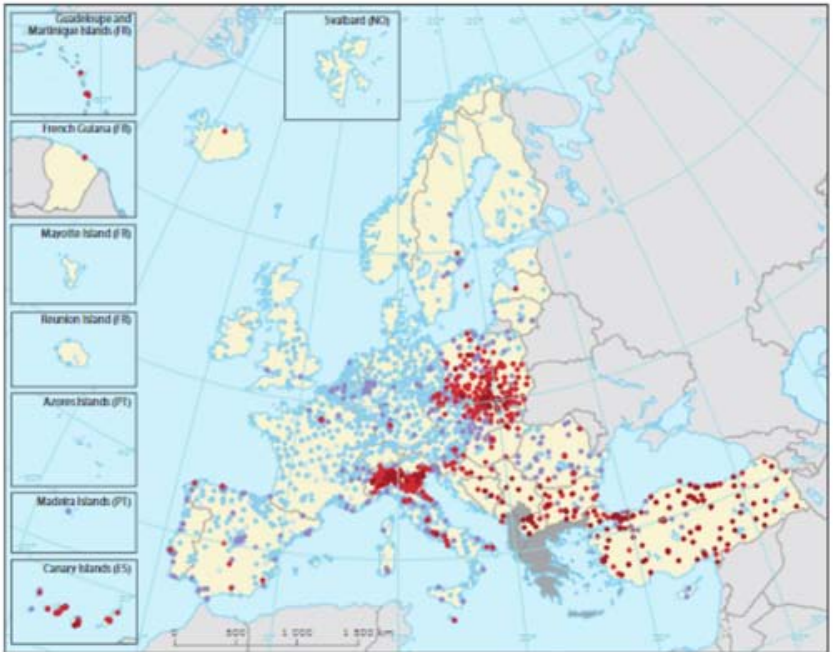

\begin{tabular}{|c|c|}
\hline \multicolumn{2}{|c|}{$\begin{array}{l}90.4 \text { percentile of PM ndaly } \\
\text { concentrations in } 2017\end{array}$} \\
\hline$\mu g / m^{3}$ & \\
\hline & $\leq 20$ \\
\hline & $20-40$ \\
\hline & 10.50 \\
\hline & 50-75 \\
\hline & $>75$ \\
\hline$\square$ & No data \\
\hline$\square$ & $\begin{array}{l}\text { Countries/regions } \\
\text { not included in the } \\
\text { data exchange } \\
\text { process }\end{array}$ \\
\hline
\end{tabular}

Note: Obseved concentrations of PM, in 2017, The possibility of suberacting contributions to the measured concentrations from

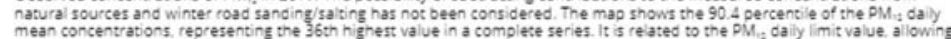
35 exceecances of the $50 \mathrm{\mu g} / \mathrm{m}^{2}$ threshold over 1 year. Dots in the last wo colour casegories indicate stations with concentratoons above Source: EEA. $2019 \mathrm{C}$

Figure 5. Concentrations of PM10, 2017 - daily limit value (44).

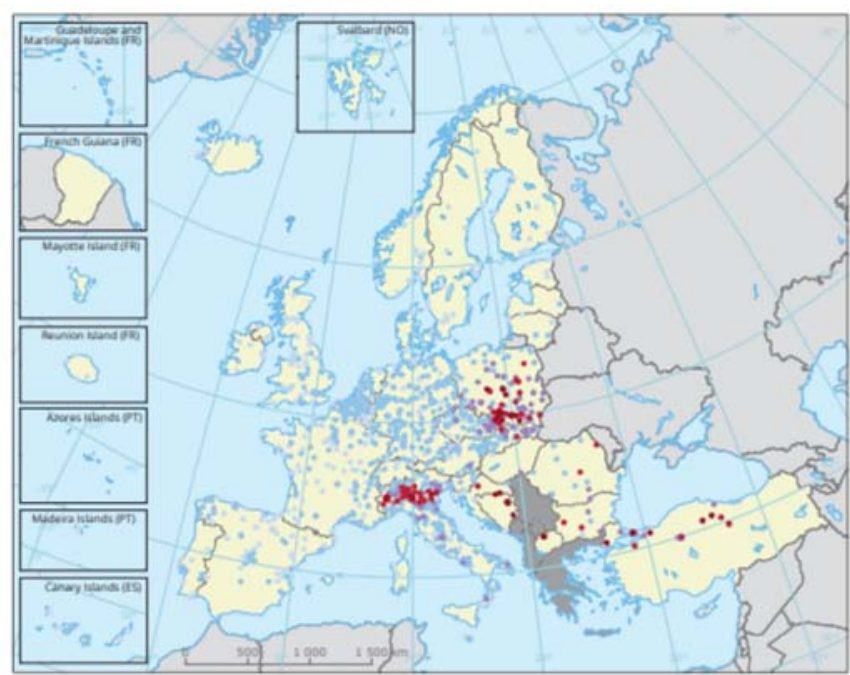

Annual mean PM
concentrations in 2017

$\mu \mathrm{g} / \mathrm{m}^{3}$

$\leq 10$

$: 10-20$
$: 20-25$

- $25-30$

- $>30$

No data

Countries/regions data exchange process

Note: Observed concentrations of $\mathrm{PM}_{23}$ in 2017. The possibility of subtracting contributions to the measured concentrations from natural sources and winter road sanding/salting has not been considered. Dots in the last two colour categories indicate stations reporting
concentrations above the EU annal ilinit value $\left(25 \mu \mathrm{g} / \mathrm{m}^{\prime}\right.$ ). Dots in the first colour category indicate stations reporting values below the WHO AQG for PM:s $\left(10 \mathrm{\mu g} / \mathrm{m}^{2}\right)$. Only stations with more than $75 \%$ of valid data have been included in the map. 


\section{Administrative issues}

Administrative organisation of Italy, bias, and bureaucracy. Italy is organized in 20 regions that have a great level of autonomy including different health systems. This autonomy gave the power to the various regions to decide the way to confront COVID-19 pandemic, taking different measures and applying different in-house made protocols. This stand also for municipalities inside the regions. This autonomy resulted in valuable time being lost until a more harmonised strategy could be applied.

In the beginning of the outbreak, and though a centralized taskforce was in place from the 22 January, a significant number of politicians and scientists seemed to underestimate the risk, producing controversary and some misleading claims. As an example, though at 23 February the President of Lombardi Region announced the first restrictive measures (6), on 27 February, a campaign was launched by the Milan Mayor, with the logo 'Milan don't stop' ('Milano non si ferma'), promoting mobility, aiming to protect people from being afraid, and based on the belief that the possibility of a serious outbreak was an exaggeration.

Though, information from China was already available and many scientists globally warned about the risk of a great outbreak, this knowledge was not used efficiently, resulting in the fast spread of COVID-19 in the population. The fact that Milan and Bergamo areas have three international airports and a great number of visitors from all over the world, for business and tourism, the effect of this international influx of people was probably underestimated.

After the beginning of the spread, authorities failed to inform the citizens promptly. Communication on events where positive cases where identified were not announced publicly or they were announced only at community level. Consequently, a large number of citizens initially took no measures to restrict contact with infected persons. Decision-making for weeks was not based on a prevention logic, but rather following the already existing cases. Restriction of mobility among areas in all Italy was decided after closure of universities and the transfer of students from Northern Italy to the whole territory.

Another key factor that prevents stopping the COVID-19 spread on-time is related to the extreme bureaucracy and the lack of flexibility in decision making. Public administration and public officers' culture demands following strictly procedures even in the case that are not fit-for-purpose and not result-oriented, minimizing the capacity to operate with flexibility and under extreme conditions where procedures are not in place. Serious delays still exist in communicating test results, end of quarantine certificates, etc.

The collapse of the health system. The Italian health system in the affected areas has been overwhelmed by the massive increase in the number of patients with the new coronavirus and is currently struggling to cope. The lesson learned in the devastated Northern of Italy is that the infection spread should be controlled before the healthcare system reaches the saturation point. Saturation of the health system leads to a tremendous increase of deaths and undermines the efficacy of the medical staff performance. One of the worst fears of the Italian government is that as the virus starts to spread to the south of the country, much poorer and much less equipped, if the experience of Northern Italy is repeated in the south.

The latest data show that medical personnel make up ca. 9\% of the total cases of COVID-19 in Italy, much higher than the percentage claimed in China. The high rate of infections among healthcare professionals is an important problem because those infected must be isolated and cannot work for at least 14 days, further weakening the already exhausted workforce. The vulnerability of the medical personnel is related to their daily contact with infected patients (patients with an important viral load) as well as asymptomatic. Also, due to the characteristic demand in the medical sector, which in some cases implies the lack of a healthy lifestyle, sleep deprivation and chronic fatigue, the susceptibility to viral infection is increased. Not infrequently, those in the medical field come to have the most severe forms of infection. The high proportion of healthcare professionals with COVID-19 in Italy is a strong warning to the world: protecting healthcare personnel should be number one priority.

Though Northern Italy has a good health system, it was found unprepared to deal with the pandemic. Personal protection equipment was not fully available for the medical staff and there was no effort to prohibit citizens to take out of market a huge number of masks without need. Lack of hand sanitizers for the general population were sold out already from day 1 .

Testing strategy. While the original thought of Italian authorities was to test both symptomatic and asymptomatic, on February 25, Italy changed its rt-PCR testing strategy for suspected cases of SARS-CoV-2 infection. The Ministry of Health then issued recommendation to prioritize testing for patients with clinical symptoms, suspected of COVID-19 and requiring hospitalization. Testing was limited to those with mild symptoms. Asymptomatic cases even after contact with positive cases were not tested. This testing strategy probably led to a high proportion of positive results vs tests performed (21.5\%, 97,689 positive cases out of 454,030 tested until $30 \mathrm{March}$ ) and an apparent increase in fatality. This is because, in the absence of testing patients with milder forms of disease and asymptomatic, the real denominator (real number of positive cases) remains unknown and certainly higher than the one reported.

South Korea had the necessary kits and equipment to perform over 10,000 tests a day. Testing started early on a large scale, setting a world record. By mid-March, South Korea conducted over 230,000 free tests, including through the drive-through system. This led to the identification of a large number of people with mild or borderline symptoms. This may be one of the reasons why South Korea has a much lower claimed fatality rate compared to Italy (1.0 vs. $7.2 \%$ - on March 17). Mass testing was one of the reasons for the successful model in controlling the spread of infection. In Germany, a leader in the UE in terms of health infrastructure, a similar pattern was followed as in South Korea, including asymptomatic persons. With an extensive network of laboratories at regional level that allows mass testing, the system can perform approximately 12,000 tests per day.

It is clear as mentioned before that comparison of fatality rate between countries is meaningful only when the same testing strategy and the same approach on considering 
Table IV. Comparison of factors relevance among Northern Italy, Germany, and Greece.

\begin{tabular}{lccc}
\hline Factor & Northern Italy & Germany & Greece \\
\hline Population density & ++ & ++ & ++ \\
Age-distribution & +++ & ++ & ++ \\
Smoking & + & ++ & ++ \\
Physical activity and Population health index & ++ & + & ++ \\
In-door social life & ++ & + & ++ \\
Family habits & +++ & NA & - \\
Environmental factors & +++ & ++ \\
Administrative organisation, bias, and bureaucracy & +++ & NA \\
The collapse of the health system & ++ & - \\
Testing strategy & ++
\end{tabular}

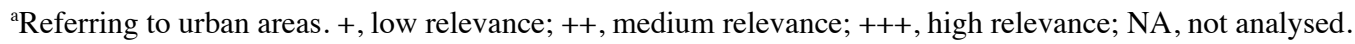

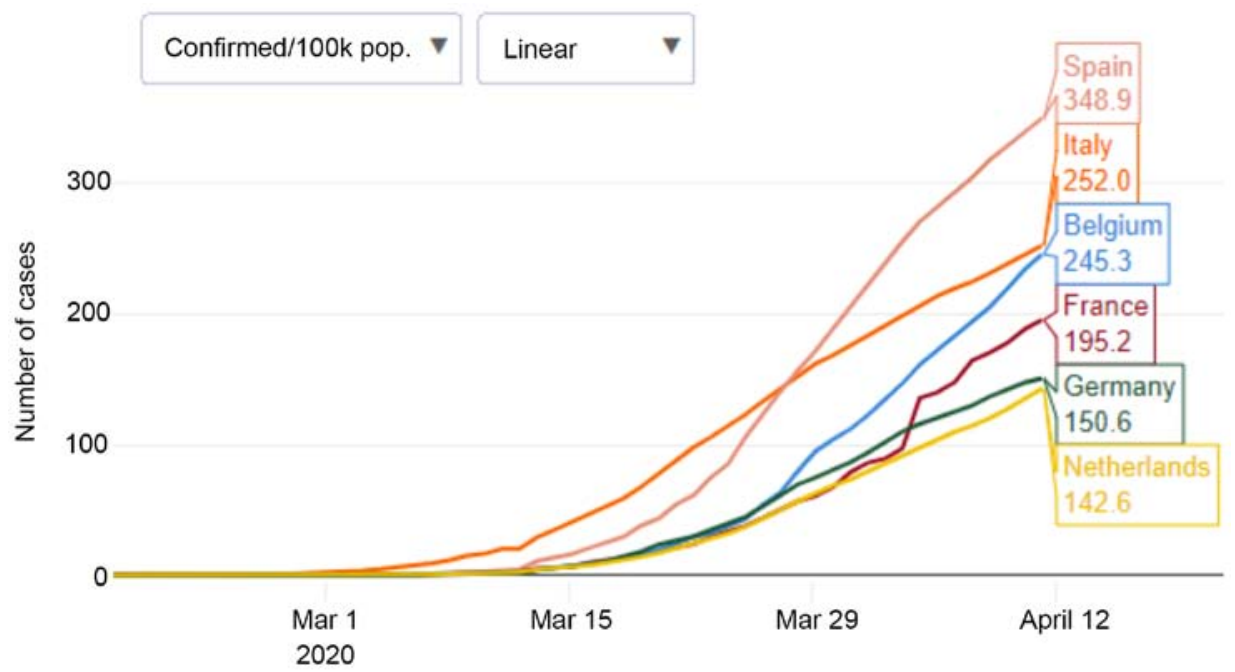

Figure 7. Cumulative cases of COVID-19 in various countries (48).

deaths as COVID-19 deaths, is applied. It is apparent that full testing from the very beginning allows to form the best strategy to prevent spread of infection and to estimate better the real fatality. In the absence of such possibility (due to no testing availability or financial reasons), restriction of citizens mobility is necessary to minimises the spread. Wide testing as measure to decrease spread when the infection curves are in maximum and restriction measures are in place are of low value. However, such strategy can still give a better idea of the real 'picture' and it might be deemed necessary when re-opening will be considered. In this case, the kind of test, its accuracy and sensitivity, and data regarding the degree of immunity that can be developed after contamination, should be considered.

\section{Discussion}

As shown in Fig. 7, global epidemiological data indicate that the epidemic evolution in each country follows different curves, with different infection rates, different figures regarding the number of positive cases, the presumed percentage of infected population and the number of related deaths. The reason for these differences is clearly multiparametric and is related to the factors analysed above, and possibly others. The evaluation of which factor is more specific for Northern Italy and which might contribute the most is quite complex and with high uncertainty. For this evaluation, we compared the relevance of these factors for four different cases; Northern Italy, Germany (central Europe, high positives, low deaths), and Greece (south Europe, low positives, low deaths) using a scale of relevance from 1 to 3+ (Table IV). Greece up to 10 April had 2,011 positive cases (ca. 20 per 100,000 people) and 90 deaths (47).

Patient comorbidities were not evaluated as they are highly related to the age distribution.

As discussed before, population density, age distribution, and physical activity combined with the population health index are factors with very similar figures among various countries (Italy, German and Greece in our example) and though they play a role in a pandemic cannot be considered specific for Italy. Regarding smoking it appears that northern Italians smoke much less than in other areas, where the COVID-19 curves have a better evolution (e.g., Greece). In-door social 
life is also a characteristic common in most of the central and north European countries with better COVID-19 evolution and though it can be considered as a contributing factor, this is not enough to explain the differences. Family habits are mentioned in various analyses as a key factor for the difference of epidemic evolution between Italy and Germany. However, it is generally acceptable that Greece as well as S. Italy have in overall even more strict family ties than in Northern Italy. Though, the evolution of the epidemic is better in these areas. The issue of pollution of Po valley is a point that could be considered as specific for Northern Italy. But again, given the fact that also Greece (mainly in the area of Athens) as well as some areas of Germany also have high air contamination, it remains questionable if this is the key factor for the observed differences of the contagious curves. The exact details for the testing strategies are not available and a comparison cannot be done securely. However, data on April 11 have shown that Italy tested slightly more individuals than Germany ( 16,708 vs. 15,730 per million persons), and many more than Netherlands $(5,926)$ and Greece $(4,055)(49)$, where the evolution of the contagion is much more benign in all aspects.

Based on our analysis the administrative organisation issues, human bias, and bureaucracy in relevance to the epidemic seems to be the key factors for the extreme outbreak in Northern Italy. Human bias could be considered the first and most important factor. In the fields of psychology and sociology the effects of bias in cases of danger and crisis are well known. As it is already shown in studies made particularly for the case of COVID-19, people tend to be overoptimistic considering that the issue is not related to them $(50,51)$. This optimism together with emotional reactions leading to ignore important numeric information, prioritizing freedom over security, the perception that the danger is too far (China) (51), and the socioeconomic issues related to an epidemic are factors that delay a rapid and correct reaction in the beginning of an epidemic. These elements together with the administrative and bureaucratic issues already discussed led to a considerable delay in taking efficient measures against the pandemic in Northern Italy leading to an excessive spread in the very first stage (ca. all February) which is still difficulty to put under control. On the contrary, countries that managed to take measures very fast and applied them using centralized administration and IT tools managed to keep the spread under control (e.g., Greece).

The collapse of the health system is clearly the key factor for the increased number of deaths. When infection is spread so rapidly and a great number of patients is accumulated at the same time in the same area, the local health systems can easily pass their capacity. Unfortunately, this happened not only in Northern Italy but also in many other countries or areas, up to now, including Spain, UK, New York, and others.

\section{Conclusions and lesson learned}

Different epidemic contributing factors were discussed, addressing those specific for Northern Italy, and which probably contributed the most in the specific case of extreme outbreak. Though all factors have some contribution, we consider that the key factors that allowed the high spread of infections, were that of existing bias, administrative organisa- tion, and bureaucracy. The high number of deaths is related to the collapse of the health system. Apparently, the high number of deaths is also a secondary result of the increase in the number of positive cases.

The lesson learned from the Northern Italy COVID-19 outbreak case is that preparedness against infectious outbreaks is of key importance. The faster the better. Politicians and scientist should be alerted and ready to deal with such a case having beforehand established precise emergency protocols. Contact tracing and a fast, high rate of testing are key to mitigating and, ultimately, confining the disease; these measures will inform those that have been infected and those that are actively infected, respectively. Emergency protocols should cover all aspects of an epidemic, including activation of emergency measures in the health system, legislative transformations, clear communication lines, risk communication issues, and existence/development of fit-for-purpose IT tools. In addition, strategic/proactive measures, which, if enacted rigorously, would end most of the concern about viral exposure translating into viral infection, are needed. Politicians and involved scientist should also be well aware about the psychological dimension of the human reactions and people trained in risk management and risk communication should be involved. The research in the area of infections should be further enhanced using the up to now knowledge and experience. Concluding, it is now clear that in the absence of vaccine, of appropriate medicines and of immediately available test (as for every new virus), the only possible measure that can be taken in order to avoid an outbreak is imposing mobility restrictions as fast is possible. In the case of Greece, where such measures were imposed very fast, no exponential increase of infection is observed up to now. Italy used the same strategy with delay and an outbreak was inevitable, but it seems that after 6 weeks the peak is reached. Though the financial impact of the restriction strategy is important, minimizing the magnitude and the duration of emergency can allow for a fast re-opening.

\section{Acknowledgements}

Not applicable.

\section{Funding}

No funding was received.

\section{Availability of data and materials}

Not applicable.

\section{Authors' contributions}

Conceptualization AT, DC, MG, DS, AOD, and DAS; validation, research, resources, data reviewing, and writing MG, DS, OA, DP, DT, RK, VR; review and editing, MG, AOD, AT, MA and DC. All authors read and approved the final manuscript.

\section{Ethics approval and consent to participate}

Not applicable. 


\section{Patient consent for publication}

Not applicable.

\section{Competing interests}

DAS is the Editor-in-Chief for the journal, but had no personal involvement in the reviewing process, or any influence in terms of adjudicating on the final decision, for this article. The other authors declare that they have no competing interests.

\section{References}

1. Remuzzi A and Remuzzi G: COVID-19 and Italy: What next? Lancet 395: 1225-1228, 2020.

2. Wordometer: Coronavirus Italy, 2020.https://www.worldometers info/coronavirus/country/italy/. Updated April 15, 2020.

3. Ministero della Salute: COVID-19 - Situazione in Italia. http:// www.salute.gov.it/portale/nuovocoronavirus/dettaglioContenutiNuovoCoronavirus.jsp?area $=$ nuovoCoronavirus $\& \mathrm{id}=5351 \&$ lin gua=italiano\&menu=vuoto. Updated April 14, 2020.

4. Istituto Superiore di Sanità: Sorveglianza Integrata COVID-19 in Italia, AGGIORNAMENTO 30 marzo 2020 (2020g). https://www.epicentro.iss.it/coronavirus/bollettino/ Infografica 30marzo\%20ITA.pdf. Accessed February 27, 2020.

5. Istituto Superiore di Sanità: Characteristics of COVID-19 patients dying in Italy. Report based on available data on April 13th, 2020. https://www.epicentro.iss.it/en/coronavirus/ bollettino/Report-COVID-2019_13_april_2020.pdf.

6. Ministero Della Salute: Misure urgenti in materia di contenimento e gestione dell'emergenza epidemiologica da COVID-19. Regione Lombardia (20A01273). Official Journal of the Italian Government (Gazzetta Ufficiale), 2020. https://www.gazzettaufficiale.it/eli/id/2020/02/25/20A01273/sg. Accessed February 23 , 2020

7. Regione Lombardia: Interactive map, 2020. http://lispa.maps arcgis.com/apps/opsdashboard/index.html\#/637ec3dc28ec4ea59 1cc5c724f127701. Updated April 14, 2020.

8. Ministero della Salute: Brusaferro (Iss): 'La curva del contagio segnala una situazione in decrescita ma non deve farci abbassare la guardia'. http://www.salute.gov.it/portale/nuovocoronavirus/ dettaglioNotizieNuovoCoronavirus.jsp?lingua=italiano\&menu= notizie \&p=dalministero\&id=4444. Accessed April 10, 2020

9. Giovanetti M, Benvenuto D, Angeletti S and Ciccozzi M: The first two cases of 2019-nCoV in Italy: Where they come from? J Med Virol 92: 518-521, 2020.

10. La Repubblica: Coronavirus, un anziano colpito a gennaio: il 'paziente uno' prima di Mattia. https://www.repubblica.it/ cronaca/2020/03/30/news/coronavirus_paziente_uno-252673269/. Accessed March 30, 2020.

11. The Guardian: 'As if we were the disease': coronavirus brings prejudice for Italy's Chinese workers.https://www.theguardian.com/ global-development/2020/mar/25/as-if-we-were-the-disease-coronavirus-brings-prejudice-for-italys-chinese-workers. Accessed March 25, 2020

12. Li W, Zhang C, Sui J, Kuhn JH, Moore MJ, Luo S, Wong SK, Huang IC, Xu K, Vasilieva N, et al: Receptor and viral determinants of SARS-coronavirus adaptation to human ACE2. EMBO J 24: 1634-1643, 2005

13. World Atlas: European Countries By Population Density, 2017. https://www.worldatlas.com/articles/ european-countries-by-population-density.html. Updated August 1, 2017.

14. Wikipedia: Wuhan. https://en.wikipedia.org/wiki/Wuhan Updated April 13, 2020.

15. World Population Review: Wuhan Population, 2020. https://worldpopulationreview.com/world-cities/wuhan-population/. Updated April 14, 2020.

16. Statista: COVID-19 cases per million inhabitants: A comparison https://www.statista.com/chart/21176/COVID-19-infection-dens ity-in-countries-most-total-cases/. Accessed April 8, 2020.

17. Eurostat: Population structure and ageing, 2019. https://ec.europa eu/eurostat/statistics-explained/index.php/Population_structure and_ageing\#Median_age_is_highest_in_Italy. Updated July 2020 .
18. Istituto Superiore di Sanità: CS N¹2/2019 - Giornata Mondiale Senza Tabacco: Fumano Ancora Due Italiani Su Dieci, Al Sud La Percentuale Piu' Alta Di Fumatrici (2020c). https://ufficiostampa. iss.it/?p=1840. Accessed March 30, 2019.

19. Statista: Smoking rates in Germany. https://www.statista.com/ chart/20011/share-of-the-population-who-smoked-in-german-fe deral-states/. Accessed November 19, 2019.

20. Istituto Superiore di Sanità: Politiche di promozione dell'attività fisica il contrasto delle malattie cardiovascolari (2020d). https:// www.epicentro.iss.it/attivita_fisica/attivita-fisica-prevenzione -cardiovascolare. Accessed February 13, 2020.

21. Istituto Superiore di Sanità: La sorveglianza Passi d'Argento (2020e). https://www.epicentro.iss.it/passi-argento/dati/attivita. Accessed February 28, 2020.

22. Eurostat: Overweight and obesity - BMI statistics, 2014. https:// ec.europa.eu/eurostat/statistics-explained/index.php/Overweight_ and_obesity_-_BMI_statistics.

23. Istituto Superiore di Sanità: La sorveglianza Passi d'Argento (2020f). https://www.epicentro.iss.it/passi-argento/dati/ obesita\#dati. February 28, 2019.

24. Costa C, Santana P, Dimitroulopoulou S, Burstrom B, Borrell C, Schweikart J, Dzurova D, Zangarini N, Katsouyanni K, Deboseree P, et al: Population Health Inequalities Across and Within European Metropolitan Areas through the Lens of the EURO-HEALTHY Population Health Index. Int J Environ Res Public Health 16: 836, 2019.

25. Miller LJ and Lu W: Economics. These Are the World's Healthiest Nations. Bloomberg, 2019. https://www.bloomberg. com/news/articles/2019-02-24/spain-tops-italy-as-world-s-healt hiest-nation-while-u-s-slips. Accessed February 24, 2019.

26. Istituto Superiore di Sanità: Characteristics of COVID-19 patients dying in Italy. Report based on available data on March 26th, 2020. https://www.epicentro.iss.it/coronavirus/bollettino/ Report-COVID-2019_26_marzo_eng.pdf.

27. Huang C, Wang Y, Li X, Ren L, Zhao J, Hu Y, Zhang L, Fan G, Xu J, Gu X, et al: Clinical features of patients infected with 2019 novel coronavirus in Wuhan, China. Lancet 395: 497-506, 2020.

28. Hoffmann M, Kleine-Weber H, Schroeder S, Krüger N, Herrler T, Erichsen S, Schiergens TS, Herrler G, Wu NH, Nitsche A, et al: SARS-CoV-2 cell entry depends on ACE2 and TMPRSS2 and is blocked by a clinically proven protease inhibitor. Cell: May 4 , 2020 (Epub ahead of print).

29. Docea AO, Tsatsakis A, Albulescu D, Cristea O, Zlatian O, Vinceti M, Moschos SA, Tsoukalas D, Goumenou M, Drakoulis N, et al: A new threat from an old enemy: Re-emergence of coronavirus (Review). Int J Mol Med 45: 1631-1643, 2020.

30. Shi S, Qin M, Shen B, Cai Y, Liu T, Yang F, Gong W, Liu X, Liang J, Zhao Q, et al: Association of cardiac injury with mortality in hospitalized patients with COVID-19 in Wuhan, China. JAMA Cardiol: Mar 25, 2020 (Epub ahead of print).

31. European Society of Cardiology: Position Statement of the ESC Council on Hypertension on ACE-Inhibitors and Angiotensin Receptor Blockers. https://www.escardio.org/Councils/ Council-on-Hypertension-(CHT)/News/position-statement-of-theesc-council-on-hypertension-on-ace-inhibitors-and-ang. Accessed March 13, 2020.

32. American College of Cardiology: COVID-19 Clinical Guidance. For the Cardiovascular Care Team. https://www.acc.org// / media/Non-Clinical/Files-PDFs-Excel-MS-Word-etc/2020/02/ S20028-ACC-Clinical-Bulletin-Coronavirus.pdf. Accessed March 6, 2020

33. Zhou F, Yu T, Du R, Fan G, Liu Y, Liu Z, Xiang J, Wang Y, Song B, Gu X, et al: Clinical course and risk factors for mortality of adult inpatients with COVID-19 in Wuhan, China: A retrospective cohort study. Lancet 395: 1054-1062, 2020.

34. Wu Z and McGoogan JM: Characteristics of and important lessons from the Coronavirus disease 2019 (COVID-19) outbreak in China, summary of a report of 72,314 cases from the Chinese Center for disease control and prevention. JAMA 323: 1239-1242, 2020.

35. Xia Y, Jin R, Zhao J, Li W and Shen H: Risk of COVID-19 for patients with cancer. Lancet Oncol 21: e180, 2020.

36. Liang W, Guan W, Chen R, Wang W, Li J, Xu K, Li C, Ai Q, Lu W, Liang H, et al: Cancer patients in SARS-CoV-2 infection: A nationwide analysis in China. Lancet Oncol 21: 335-337, 2020.

37. Kuba K, Imai Y, Rao S, Gao H, Guo F, Guan B, Huan Y, Yang P, Zhang Y, Deng W, et al: A crucial role of angiotensin converting enzyme 2 (ACE2) in SARS coronavirus-induced lung injury. Nat Med 11: 875-879, 2005. 
38. Cheng Z, Zhou J, To KK, Chu H, Li C, Wang D, Yang D, Zheng S, Hao K, Bossé Y, et al: Identification of TMPRSS2 as a susceptibility gene for severe 2009 pandemic $\mathrm{A}(\mathrm{H} 1 \mathrm{N1})$ influenza and A(H7N9) influenza. J Infect Dis 212: 1214-1221, 2015.

39. Lu R, Zhao X, Li J, Niu P, Yang B, Wu H, Wang W, Song H, Huang B, Zhu N, et al: Genomic characterization and epidemiology of 2019 novel coronavirus: implications for virus origins and receptor binding. Lancet 395: 565-574, 2020

40. Asselta R, Paraboschi EM, Mantovani A and Duga S: ACE2 and TMPRSS2 variants and expression as candidates to sex and country differences in COVID-19 severity in Italy. medRxiv: doi. org/10.1101/2020.03.30.20047878.

41. Eurostat: Estimated average age of young people leaving the parental household by sex. https://appsso.eurostat.ec.europa. eu/nui/show.do?dataset=yth_demo_030\&lang=en. Updated February 24, 2020.

42. Goumenou M, Spandidos DA and Tsatsakis A: [Editorial] Possibility of transmission through dogs being a contributing factor to the extreme Covid-19 outbreak in North Italy. Mol Med Rep 21: 2293-2295, 2020

43. European Space Agency: Po Valley, Italy. https://www.esa.int/ ESA_Multimedia/Images/2019/05/Po_Valley_Italy. Accessed May 17, 2019.

44. European Environment Agency: Air quality in Europe - 2019 report. No 10/2019. https://www.eea.europa.eu/publications/air-quality-in-europe-2019. Accessed June 24, 2019.

45. European Environment Agency: Air polution profile: Italy (2019b). https://www.eea.europa.eu/themes/air/country-fact-she ets/2019-country-fact-sheets/italy.
46. Sarigiannis DA, Kermenidou M, Nikolaki S, Zikopoulos D and Karakitsios SP: Mortality and morbidity attributed to aerosol and gaseous emissions from biomass use for space heating. Aerosol Air Qual Res 15: 2496-2507, 2015.

47. Greek Civil Protection: Press Conference for the COVID-19 evolution. https://www.civilprotection.gr/el/enimerosi-apo-ton-y fypoyrgo-politikis-prostasias-kai-diaheirisis-kriseon-niko-hard alia-kai-ton-14. Accessed April 10, 2020.

48. Johns Hopkins University of Medicine: Coronavirous Resource Center, 2020. https://coronavirus.jhu.edu/data/cumulative-cases. Updated April 14, 2020.

49. Wordometer: Confirmed Cases and Deaths by Country, Territory, or Conveyance. https://www.worldometers.info/ coronavirus/\#countries. Updated April 15, 2020.

50. Kuper-Smith B, Doppelhofer L, Oganian Y, Rosenblau G and Korn C: Optimistic beliefs about the personal impact of COVID-19. PsyArXiv: doi:10.31234/osf.io/epcyb.

51. Van Bavel JJ, Baicker K, Boggio P, Capraro V, Cichocka A, Crockett M, Cikara M, Crum A, Douglas K, Druckman J, et al: Using Social and Behavioural Science to Support COVID-19 Pandemic Response. PsyArXiv: doi.org/10.31234/osf.io/y38m9.

This work is licensed under a Creative Commons Attribution-NonCommercial-NoDerivatives 4.0 International (CC BY-NC-ND 4.0) License. 